\title{
Occupancy estimation of jaguar Panthera onca to assess the value of east-central Mexico as a jaguar corridor
}

\author{
Lisanne S. Petracca, O. Eric Ramírez-Bravo and Lorna Hernández-Santín
}

\begin{abstract}
The use of wildlife corridors to maintain landscape connectivity has become increasingly relevant to the conservation of wide-ranging species, including the jaguar Panthera onca. Jaguars are particularly threatened in Mexico, where corridor linkages are tenuous as a result of habitat fragmentation. Our study assessed a section of potential corridor south of the Sierra Madre Oriental in eastern Mexico. We conducted 245 interviews with local inhabitants in $14036-\mathrm{km}^{2}$ sampling units over a 5-month period and compiled detection histories for jaguars and five prey species: collared peccary Pecari tajacu, red brocket deer Mazama americana, white-tailed deer Odocoileus virginianus, spotted paca Agouti paca, and nine-banded armadillo Dasypus novemcinctus. These detection histories were then analysed using site occupancy modelling. Each sampling unit was assigned a probability of habitat use based on (1) the two smaller prey species (paca and armadillo) and (2) at least two of the larger prey species (collared peccary and two deer species) using habitat in that unit. This probability estimate was considered a proxy for the prey base of each sampling unit and therefore the unit's suitability as a jaguar corridor. Although the prey base in some areas appears adequate to support a jaguar population, large-scale development projects and the paucity of jaguar sign are major obstacles to this region's potential as a jaguar corridor. Our results suggest that the eastern coast of Mexico may not be a priority area for range-wide jaguar conservation.
\end{abstract}

Keywords Connectivity, interviews, jaguar, Mexico, occupancy modelling, Panthera onca, wildlife corridor

This paper contains supplementary material that can be found online at http://journals.cambridge.org

Lisanne S. Petracca (Corresponding author) Panthera, 8 West 40th Street, 18th Floor, New York, NY 10018, USA. E-mail lpetracca@panthera.org

O. ERIC RAMíreZ-BRAVO ${ }^{*}$ Durrell Institute for Conservation Ecology, University of Kent, Canterbury, UK

LoRna HernándeZ-SANTín Departamento de Ciencias Químico-Biológicas, Universidad de las Américas, Puebla, México

*Also at: Departamento de Ciencias Químico-Biológicas, Universidad de las Américas, and CREANATURA A.C., Puebla, México

Received 12 June 2012. Revision requested 20 November 2012.

Accepted 9 January 2013. First published online 6 November 2013

\section{Introduction}

The concept of large-scale habitat connectivity via 1 protected areas and associated wildlife corridors has become a driving force in conservation of the jaguar Panthera onca (Sanderson et al., 2002; Rabinowitz \& Zeller, 2010). As human population growth continues, wildlife corridors are considered a means to prevent the loss of genetic diversity in resident wildlife populations as a result of habitat fragmentation (Beier \& Noss, 1998). The jaguar has become a model species for the implementation of such strategies in Mesoamerica because of its large home range requirement, threatened status and significant role as a keystone species and apex predator (Swank \& Teer, 1989; Sunquist \& Sunquist, 2002). A recent analysis of mitochondrial DNA from blood samples across the species' range showed high gene flow and little evidence of geographic barriers to dispersal (Eizirik et al., 2001), suggesting that large-scale habitat connectivity may still exist.

The purpose of corridors is to promote species persistence via dispersal and subsequent genetic exchange (Noss, 1987). As habitat fragmentation increases and gene flow is reduced or prevented, potential effects include a smaller effective population size and a reduction in adaptive fitness as a result of genetic drift and inbreeding (MacArthur \& Wilson, 1967; Soule \& Mills, 1998). The effects of reduced genetic exchange in felids have been well documented, particularly in relation to the Florida panther Felis concolor coryi (Hedrick, 1995). Isolated populations also suffer the negative effects of demographic and environmental stochasticity (Brown \& Kodric-Brown, 1977).

Jaguars have been shown to inhabit human-impacted areas with varying degrees of disturbance (Foster et al., 2010) but little is known about the status of jaguar populations outside protected areas (Sanderson et al., 2002). Mexico, which is at the northernmost limit of permanent jaguar range, is no exception, with most jaguar research there occurring only recently (Monroy-Vilchis et al., 2008, 2009; Grigione et al., 2009).

The range-wide analysis conducted by Rabinowitz \& Zeller (2010) was one of the first modelling exercises of jaguar habitat across its range, using six landscape characteristics to identify least-cost corridors connecting 90 known jaguar populations. As this product was derived only from geospatial analysis and expert assignment of cost values, Zeller et al. (2011) used a field-based interview method to validate jaguar and prey presence in one of the 


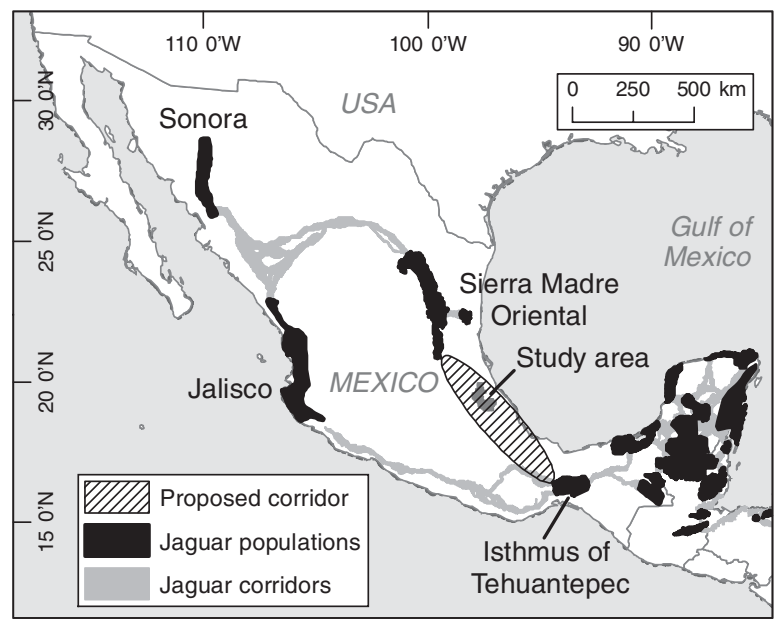

FIG. 1 Location of jaguar Panthera onca populations and modelled least-cost corridors, from Rabinowitz \& Zeller (2010). Our study assessed the suitability of a jaguar corridor along Mexico's east coast, where habitat connectivity is unknown.

least-cost corridors in Nicaragua. The interview data were analysed using site occupancy modelling, which had a simple detection/non-detection data requirement and the ability to model occupancy as a function of environmental covariates (MacKenzie et al., 2006). The protocol allowed rapid, large-scale monitoring of jaguars and their prey while compensating for imperfect detection, and allowed the authors to refine a geospatially-derived corridor using field data (MacKenzie et al., 2009; Zeller et al., 2011).

Rabinowitz \& Zeller (2010) suggested habitat connectivity along Mexico's Pacific coast via a 1,00o km corridor connecting jaguar populations in Jalisco and the Isthmus of Tehuantepec (Fig. 1). The only major jaguar population of the east coast, in the Sierra Madre Oriental, is connected to populations in Sonora and Jalisco via a tenuous $800 \mathrm{~km}$ corridor. Rabinowitz \& Zeller (2010) did not show any functional connectivity between the Sierra Madre Oriental and the Isthmus of Tehuantepec, a distance of c. $700 \mathrm{~km}$.

A large-scale analysis driven solely by geospatial data and expert assignment of cost values may not adequately represent on-the-ground conditions and could therefore overlook viable corridors. In response to this perceived shortcoming, as well as published accounts of jaguar presence in east-central Mexico (Espino-Barrios et al., 2005; MonroyVilchis et al., 2008, 2009), we proposed a potential corridor connecting jaguar populations of the Sierra Madre Oriental and the Isthmus of Tehuantepec (Fig. 1). Our study area was located in the centre of this proposed corridor (Fig. 2). Our goals were to determine jaguar presence in a little-known area of Mexico and to ascertain whether Rabinowitz \& Zeller (2010) omitted a functional corridor. We hypothesized that if connectivity remained along the east coast of Mexico there would be strong evidence of a viable jaguar population or frequent dispersers in the area.

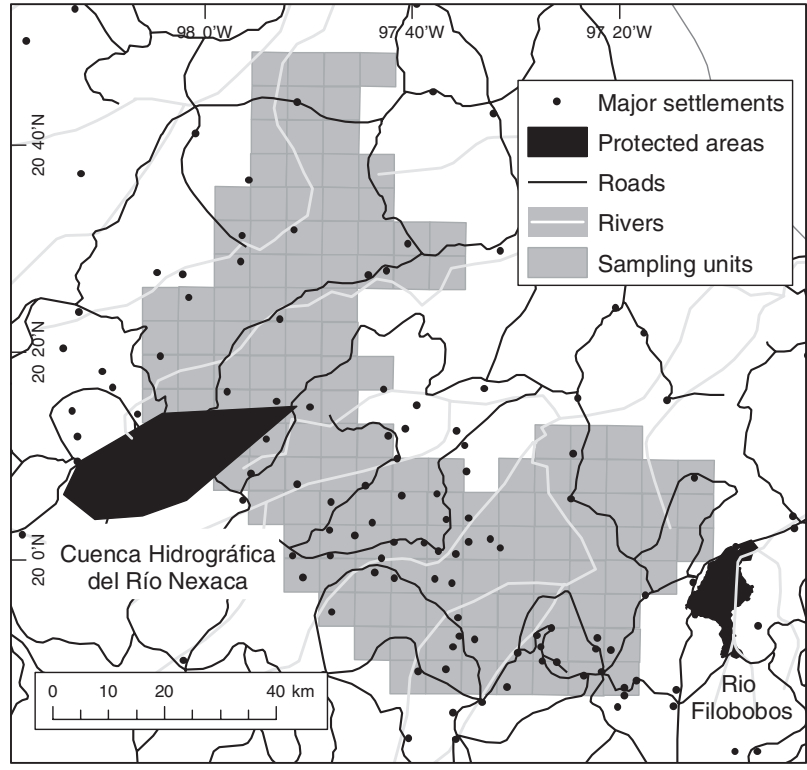

FIg. 2 The study area in north-east Puebla state, Mexico (Fig. 1).

\section{Study area}

Our study area $\left(5,040 \mathrm{~km}^{2}\right)$ was located in north-east Puebla state, in east-central Mexico (Fig. 2). The area is characterized by a north-east to south-west elevation gradient of 50-2,840 $\mathrm{m}$. The primary land-cover types are vegetation/ cropland mosaic (40\%), cropland and cropland/vegetation mosaic (35\%) and savannah (13\%). Approximately one-third of the protected area Cuenca Hidrográfica del Río Necaxa (total area $396 \mathrm{~km}^{2}$ ) lies within the western border of the study area. There are c. 730,000 inhabitants across 1,800 settlements in the region (median population size of settlements $=107$ ), mostly comprising coffee, pepper and citrus fruit-growers.

\section{Methods}

\section{Sampling design}

We divided the study area into $1406 \times 6 \mathrm{~km}$ sampling units. The sampling unit size $\left(36 \mathrm{~km}^{2}\right)$ was based on the minimum estimated jaguar home ranges in the region: 25 and $32 \mathrm{~km}^{2}$ in Jalisco and Campeche states, respectively (Ceballos et al., 2002; Nunez et al., 2002). We conducted interviews with local inhabitants over a 5-month period, using the protocol outlined by Zeller et al. (2011). Each interview from the same sampling unit was considered a separate replicate for the computation of detection probabilities.

\section{Interview protocol}

The questionnaire was designed to gather detection histories for the jaguar and five common prey species: collared 
peccary Pecari tajacu, red brocket deer Mazama americana, white-tailed deer Odocoileus virginianus, spotted paca Agouti paca, and nine-banded armadillo Dasypus novemcinctus (Weckel et al., 2006).

The interview protocol specifically targeted those who were knowledgeable about wildlife in the area, such as hunters, farmers and ranchers. Interviewees also had to have known the area for at least 1 year and have visited the area at least twice per month. The first task of the interviewer was to determine the interviewee's area of knowledge, which could span one or more sampling units. The interview questions were specific to a single sampling unit, such that the questions had to be repeated if the interviewee's area of knowledge extended to more than one sampling unit. This ensured a separate detection history for each unit.

We collected data on whether a jaguar had been positively detected in a given sampling unit within the previous year. Positive detections could include tracks, scat, vocalizations or direct sightings of a live or recently dead animal. Following a verbal description of what an interviewee had seen, we produced reference cards with photographs and tracks from various species and asked the interviewee to confirm what he or she had seen. If there was any doubt concerning the validity of the response, the data were discarded.

We also collected data on how frequently each of the five prey species was seen. Responses were categorized into four groups based on frequency of sighting: absent (not observed), rare (observed 1-5 times per year), moderately observed ( $>5$ times per year but $<2$ times per month) and frequently observed ( $\geqslant 2$ times per month). If a species was absent or rarely observed we asked interviewees why the species was not seen more frequently.

Lastly, we collected personal data from the interviewees. These data included age, sex, reason for going to the sampling unit (hunting, farming, logging, etc.), means of transportation within the sampling unit, how long they had lived in the area and how often they visited the sampling unit. These variables were then used as covariates in our models. We also inquired about impending development projects and each interviewee's personal perception of jaguars, although these data were only used to supplement the analysis.

\section{Covariates}

Site occupancy modelling uses a detection/non-detection matrix for a given species to estimate two separate parameters: likelihood of habitat use and likelihood of species detection, the latter of which is related to an observer's ability to detect the animal (MacKenzie et al., 2006). These parameters can also be modelled as a function of environmental covariates, variables that we hypothesized would influence a species' use of the landscape.
Site covariates, which influence the likelihood of habitat use by each target species, included the proportion of each sampling unit with a particular land cover (water, broadleaf forest, needleleaf forest, mixed forest, savannah, vegetation/ crop mosaic, cropland, wetland), the proportion of total forest (broadleaf, needleleaf and mixed), the proportion of total water (water and wetland), mean elevation (m), maximum elevation $(\mathrm{m})$, and distance $(\mathrm{m})$ to river, road, village and protected area. Sampling covariates, which influence the likelihood of detection, included all site covariates, with the addition of interviewee-specific variables: effort (\% of year in the field), hunter (yes/no), farmer (yes/no), and whether the interviewee travelled by foot within the sampling unit (yes/no). We could then use the model to investigate whether certain characteristics (e.g. spending more time in the field, status as a hunter, travelling by foot) increased species detection.

Land cover was derived from the GlobCover $300 \mathrm{~m}$ dataset (ESA, 2008). We obtained elevation data from the SRTM 90 m digital elevation database v. 4.o (Jarvis et al., 2008) and protected area data from the World Database on Protected Areas (IUCN \& UNEP, 2010). Layers for roads, rivers and settlements were derived from Mexico's portal for geographical information (CONABIO, 2011). All spatial data were compiled using ArcMap v. 10.0 (ESRI, Redlands, USA).

\section{Data analysis}

We used Presence v. 3.1 (Hines, 2010) to analyse the data. Interview responses regarding the presence/absence of the jaguar and its five prey species were coded as detection/nondetection matrices. There was a maximum of 12 replicates per site, with one site lacking data.

\section{Single-state and multi-state models}

For a summary of the site occupancy modelling method, see Supplementary Material 1.

Naïve occupancy values, which equate to the proportion of sampling units in which a species was positively detected, were $0.04,0.31,0.52$ and 0.29 for the jaguar, collared peccary, red brocket deer and white-tailed deer, respectively. We analysed data from these species in a single-state model.

Naive occupancy of the paca was high (0.92), suggesting that this species was ubiquitous in the study area. To address high naïve occupancy, paca data were analysed using a multi-state model developed by Nichols et al. (2007), which converted the four frequency-of-detection categories (absent, rare, moderately observed and frequently observed) into abundance states ( $0,1,2$ and 3 , respectively). This is based on the assumption that the more frequently a species or its sign was observed, the higher its relative abundance in the sampling unit. We modelled $\Psi$-cond in state 3 
$\left(\Psi-\right.$ cond $\left._{\text {states }}\right)$, which is the likelihood of species presence in the highest abundance state, in our multi-state model.

Probably because of the high naïve occupancy of the armadillo (0.97), neither a single-state nor multi-state model could be fit to the data. This resulted in a single-state model with an altered detection history such that states 0,1 and 2 were equal to o (absent) and state 3 was equal to 1 (present). Thus the armadillo was considered absent in states $0-2$ and covariates were modelled only for state 3 within a singlestate model.

\section{Model selection and model averaging}

We used Akaike's Information Criterion, using the smallsample correction (AICc), to rank the models. This method uses the principle of parsimony to produce a fitted model with the fewest necessary parameters (Burnham \& Anderson, 2002). We computed Akaike weights to determine the relative goodness of fit of each of the models. We eliminated models that contained statistically insignificant parameter estimates. In the event of multiple models with similar Akaike weights and significant and/or ecologically relevant covariates, we used model averaging to estimate probabilities of habitat use and detection (Burnham \& Anderson, 2002).

\section{Predictive maps and corridor assessment}

We divided prey species into two groups: Group I comprised the smaller species (spotted paca, armadillo) and Group II comprised the larger species (collared peccary, red brocket deer, white-tailed deer). We created two conditional statements to obtain the prey probability estimate, the probability of both Group I species and at least two Group II species using a given sampling unit. We multiplied $\Psi$ cond $\mathrm{G}_{\mathrm{I}}$, the probability that both smaller species use a given sampling unit (Supplementary Material 2, Equation 1), and $\Psi$-condG $\mathrm{G}_{\mathrm{II}}$, the probability that at least two of the larger prey species use that sampling unit (Supplementary Material 2, Equation 2).

We identified sampling units suitable for a jaguar corridor as those with a prey probability estimate of at least 0.90 (Zeller et al., 2011).

\section{Results}

We conducted 245 interviews in the 140 sampling units during June-October 2010, with a mean of 5.5 interviews per site. Interviewees were aged $18-80$ years old, with a mean age of 44 years. Ninety-six percent of interviewees were male. Interviewees spent a mean of $9.78 \pm$ SD 7.73 days per month within the sampling units. Their main purposes in the study area were farming (37\% of interviewees), cattle ranching $(24 \%)$ and hunting (16\%). Major impending development projects included road construction (52\% of projects), oil drilling (19\%) and mining (16\%).

In response to why certain prey species were not seen more frequently, the most common reasons given were hunting by humans ( $57 \%$ of responses) and deforestation (24\%).

Fifty-five percent of respondents had a negative attitude towards jaguars. The most common negative perceptions were fear ( $48 \%$ of responses) and a desire to kill jaguars $(6 \%)$.

The most predictive model for the jaguar was the null model (Table 1), which predicts habitat use based solely on the detection/non-detection matrix and is used in the absence of significant site covariates. Likelihood of detection increased if the interviewee was a hunter.

Occupancy models for the five prey species were mostly driven by elevation (Table 1 ).

Using the null model for the jaguar and averaged top models for all five prey species we created maps of probability of habitat use by sampling unit (Fig. 3).

To identify the sampling units suitable for a jaguar corridor we used a minimum prey probability estimate of 0.90 (Zeller et al., 2011). Of the 140 sampling units, 31 (22.14\%) were suitable for a corridor (Fig. 4).

\section{Discussion}

Species modelling revealed that some sampling units have an adequate prey base but lack jaguar sign. Jaguar sign of any type (direct sighting, track, scat, vocalization) was detected in only five of $140(3.60 \%)$ sampling units during the previous year, which suggests that jaguars are rare in north-east Puebla state and probably do not have a resident population within the $5,040 \mathrm{~km}^{2}$ study area.

Elevation was a major driver in the detection of the large prey species and the habitat use of the small prey species. Our study area was characterized by a sharp elevation gradient, in which the lowlands were heavily cultivated and the highlands remained forested. For this reason detection of the collared peccary and red brocket deer increased with elevation, as both species prefer forested habitats (Altrichter \& Boaglio, 2004; Tejeda-Cruz et al., 2009). Detection of the collared peccary was also associated with proximity to protected areas, which emphasizes this species' partiality to forest at a distance from human settlements (Altrichter \& Boaglio, 2004).

Contrary to results for the collared peccary and red brocket deer, detection of white-tailed deer decreased with elevation, as this species has been documented to use human-altered habitat more frequently than expected and avoid dense rainforest (Tejeda-Cruz et al., 2009). The fact that white-tailed deer habitat use was associated with increased croplands further supports this trend. 
TABLE 1 Most predictive models and untransformed coefficients of covariates for the jaguar Panthera onca and five prey species. Data for the jaguar, collared peccary, red brocket deer, and white-tailed deer were analysed using single-state models, spotted paca data were analysed using a multi-state model and armadillo data were analysed using a modified single-state model such that state $3=$ presence and states $0-2=$ absence.

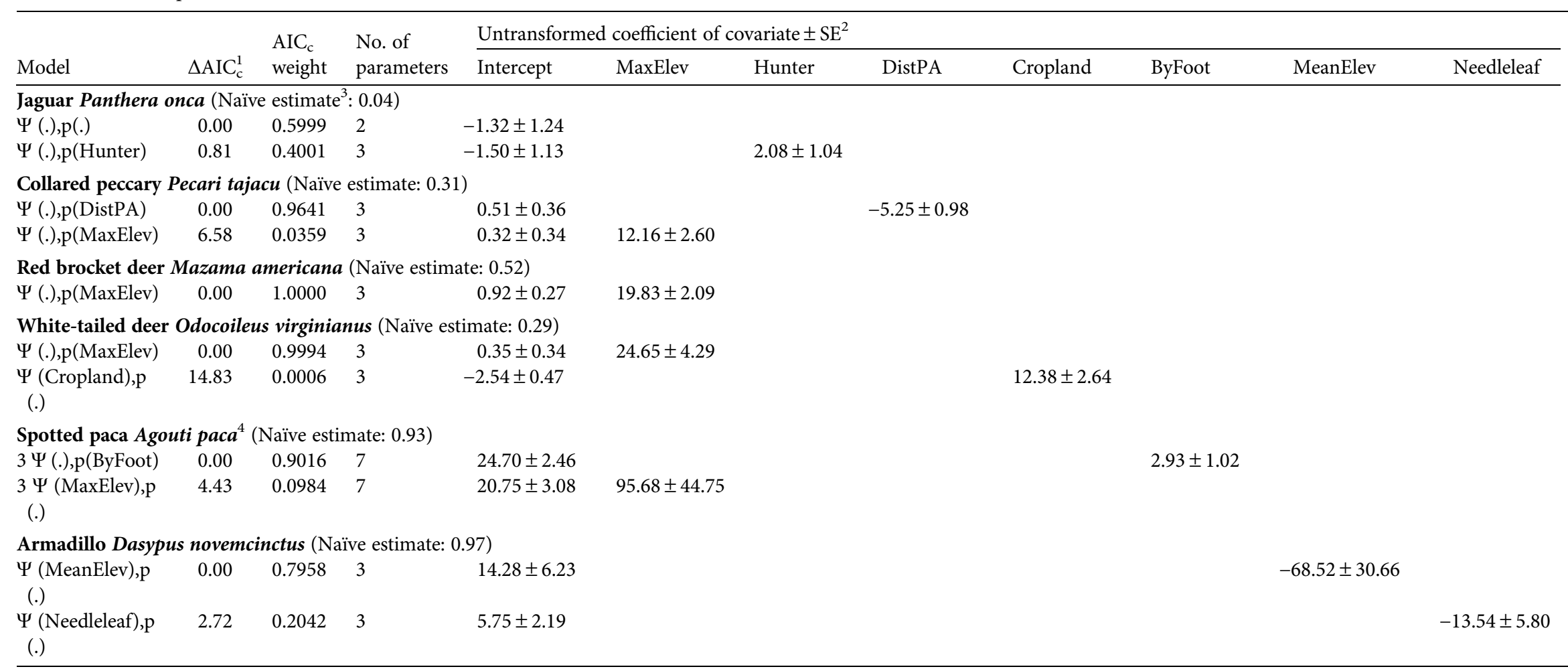

${ }^{1}$ Difference in $\mathrm{AIC}_{\mathrm{c}}$ value relative to top model

${ }^{2}$ MaxElev, maximum elevation in sampling unit; Hunter, whether or not the interviewee was a hunter (yes/no); DistPA, mean distance from sampling unit to edge of nearest protected area; Cropland, proportion of cropland in sampling unit; ByFoot, whether or not the interviewee explored the sampling unit by foot (yes/no); MeanElev, mean elevation of sampling unit; Needleleaf, proportion of needleleaf forest in sampling

${ }^{3}$ Proportion of sampling units in which species was detected

${ }^{4}$ For multistate models, coefficients are for state 3 


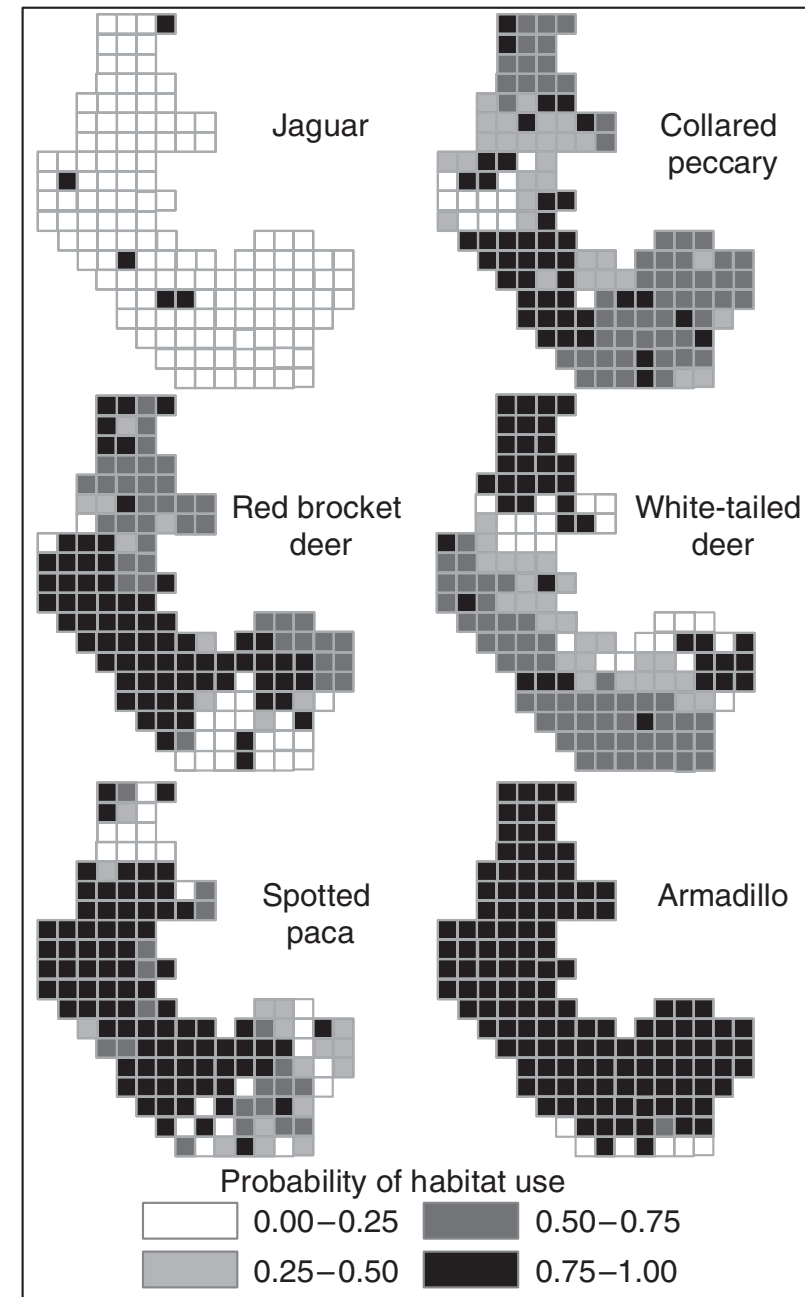

FIG. 3 Estimated probabilities of habitat use by jaguar and five prey species in the sampling units.

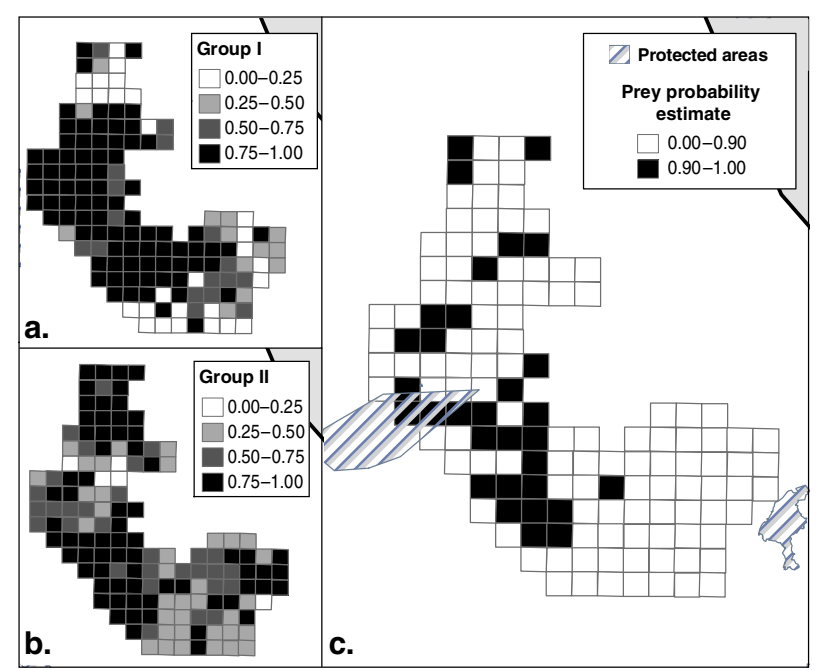

FIG. 4 (a) Probability of both the spotted paca and armadillo using habitat in each sampling unit; (b) probability of at least two of the three larger prey species using habitat in each sampling unit; and (c) probability of scenarios (a) and (b) occurring in each sampling unit.
For the spotted paca there was a positive association between habitat use in the highest abundance state and greater maximum elevation, as the paca prefers forested habitat with access to fruits, nuts and seeds (Beletsky, 2010). The association between increased detection and traversing the sampling unit by foot is obvious and suggests that walking an area will result in higher detection rates than biking or driving.

The armadillo had a positive association between habitat use and (1) lower mean elevation and (2) less needleleaf forest. Armadillos are habitat generalists capable of persisting in a variety of landscapes (Beletsky, 2010), which could explain the observed trend of armadillos using disturbed habitat at lower elevations.

The lack of jaguar sign despite the apparent abundance of prey is a cause for concern. During a 12-month period only five positive jaguar detections (three tracks, two direct sightings) in an area of $5,040 \mathrm{~km}^{2}$ were reported in $>245$ interviews. Given that carnivore home range is thought to increase with decreasing habitat quality (Logan \& Sweanor, 2001) and prey availability (Crawshaw \& Quigley, 1991), and that we based our sampling unit size on findings from more productive environments (Ceballos et al., 2002; Nunez et al., 2002), we probably underestimated the true home range size of jaguars in our study area. The use of sampling units smaller than the mean home range should have increased, rather than decreased, the detection probability in our area. The paucity of jaguar sightings by knowledgeable interviewees within such a broad area does not provide strong evidence of a resident jaguar population, nor does it suggest that this area is consistently traversed by dispersing individuals.

An additional concern is the possibility of false detection. Each jaguar detection was in a different sampling unit and therefore was not confirmed by other interviewees. One drawback of our method is that the highest observed state has no ambiguity; therefore if a jaguar has been detected at a site it is not possible for the site to be unoccupied (MacKenzie et al., 2009). This inability to account for false positives could suggest that jaguars are present when they are in fact absent from our study area. Another possibility is that these were true detections of a dispersing individual that did not have a permanent home range in the area. Thus, this region may not have a resident population but may be acting as a corridor for occasional dispersers.

If jaguars are present in the study area, large-scale development appears to be the biggest threat to the viability of the area as a jaguar corridor. Current and impending projects in the north (oil drilling, new road networks), centre (mining) and south (hydroelectric dam) will affect habitat connectivity for jaguars and other wildlife. Our prey habitat-use results, which identified isolated blocks of corridor surrounded by unsuitable units (Fig. 4), suggest fragmentation of available habitat. Of added significance 
is the predominantly negative attitude of the local people towards jaguars. In an area where people fear jaguars and some express a desire to kill them, educational outreach would be helpful to change their perspective and promote tolerance of jaguars. However, changed mindsets alone will not increase jaguar presence in this area.

Although there appears to be a prey base for jaguars in this region, the low frequency of jaguar sign, evidence of habitat fragmentation and impending large-scale development suggest that our study area does not hold great promise as a jaguar corridor. Conservation measures may be necessary to maintain and/or restore connectivity in this region.

\section{References}

Altrichter, M. \& Boaglio, G.I. (2004) Distribution and relative abundance of peccaries in the Argentine Chaco: associations with human factors. Biological Conservation, 116, 217-225.

Beier, P. \& Noss, R.F. (1998) Do habitat corridors provide connectivity? Conservation Biology, 12, 1241-1252.

Beletsky, L. (2010) Belize \& Northern Guatemala: Travellers' Wildlife Guides, 2nd edition. Interlink, Northampton, USA.

Brown, J.H. \& Kodric-Brown, A. (1977) Turnover rates in insular biogeography: effect of immigration on extinction. Ecology, $58,445-449$.

Burnham, K.P. \& Anderson, D.R. (2002) Model Selection and Multimodel Inference: A Practical Information-Theoretic Approach, 2nd edition. Springer, New York, USA.

Ceballos, G., Chavez, C., Rivera, A., Manterola, C. \& Wall, B. (2002) Tamano poblacional y conservacion del jaguar en la Reserva de la Biosfera Calakmul, Campeche, Mexico. In El Jaguar en el Nuevo Milenio (eds R. Medellin, C. Equihua, C.L.B. Chetkiewicz, P.G. Crawshaw Jr, A. Rabinowitz, K.H. Redford, et al.), pp. 403-417. Fondo de Cultura Economica, Universidad Nacional Autonoma de Mexico, and Wildlife Conservation Society, Mexico.

CONABio (Comisión Nacional para el Conocimiento y Uso de la Biodiversidad) (2011) Portal de Geoinformación. Http://www.conabio.gob.mx/informacion/gis/ [accessed 2011].

Crawshaw, P.G. \& Quigley, H.B. (1991) Jaguar spacing, activity, and habitat use in a seasonally flooded environment in Brazil. Journal of the Zoological Society of London, 223, 357-370.

Eizirik, E., Kim, J., Menotti-Raymond, M., Crawshaw, Jr, P.G., O'Brien, S.J. \& Johnson, W.E. (2001) Phylogeography, population history, and conservation genetics of jaguars (Panthera onca, Mammalia, Felidae). Molecular Ecology, 10, 65-79.

Espino-Barrios, V.O.A., Viera, R.G., Martinez, R.R., Zepeda, J.S.H., Correo, J.C.C. \& Torres, F.J.T. (2005) Diversificacion productiva en el campo experimental Las Margaritas, Puebla, Mexico. Archivos de Zootecnia, 54, 197-203.

ESA (European Space Agency) (2008) GlobCover Land Cover v. 2 2008 database. Http://ionia1.esrin.esa.int/ [accessed 2011].

Foster, R.J., Harmsen, B.J. \& Doncaster, C.P. (2010) Habitat use by sympatric jaguars and pumas across a gradient of human disturbance in Belize. Biotropica, 42, 724-731.

Grigione, M.M., Menke, K., Lopez-Gonzalez, C., List, R., BANDA, A., CARrera, J., et al. (2009) Identifying potential conservation areas for felids in the USA and Mexico: integrating reliable knowledge across an international border. Oryx $43,78-86$.
Hedrick, P.W. (1995) Gene flow and genetic restoration: the Florida panther as a case study. Conservation Biology, 9, 96-1007.

Hines, J.E. (2010) PRESENCE v. 3.1. Http://www.mbr-pwrc.usgs.gov/ software/presence.shtml [accessed 2011].

IUCN \& UNEP (2010) The World Database on Protected Areas. Http://www.protectedplanet.net [accessed 2011].

Jarvis, A., Reuter, H.I., Nelson, A., Guevara, E. (2008) Hole-filled SRTM for the globe v. 4. Http://srtm.csi.cgiar.org [accessed 2011].

Logan, K.A. \& Sweanor, L.L. (2001) Desert Puma: Evolutionary Ecology and Conservation of an Enduring Carnivore. Island Press, Washington, DC, USA.

MacArthur, R.H. \& Wilson, E.O. (1967) The Theory of Island Biogeography. Princeton University Press, Princeton, USA.

MacKenzie, D.I., Nichols, J.D., Royle, J.A., Pollock, K.H., BAiley, L.L. \& Hines, J.E. (2006) Occupancy Estimation and Modeling: Inferring Patterns and Dynamics of Species Occurrence. Academic Press, Boston, USA.

MacKenzie, D.I., Nichols, J.D., Seamans, M.E. \& Gutiérrez, R.J. (2009) Modeling species occurrence dynamics with multiple states and imperfect detection. Ecology, 90, 823-835.

Monroy-Vilchis, O., Sanchez, O., Aguilera-Reyes, U., SuArez, P. \& URIos, V. (2008) Jaguar (Panthera onca) in the state of Mexico. The Southwestern Naturalist, 53, 533-537.

Monroy-Vilchis, O., RodrigueZ-Soto, C., ZarcoGonzalez, M. \& Urios, V. (2009) Cougar and jaguar habitat use and activity patterns in central Mexico. Animal Biology, 59, 145-157.

Nichols, J.D., Hines, J.E., MacKenzie, D.I., Seamans, M.E. \& Gutierrez, R.J. (2007) Occupancy estimates and modeling with multiple states and state uncertainty. Ecology, 88, 1395-1400.

Noss, R.F. (1987) Corridors in real landscapes: a reply to Simberloff and Cox. Conservation Biology, 1, 159-164.

Nunez, R., Miller, B. \& Lindzey, F. (2002) Ecologia del jaguar en la Reserva de la Biosfera Chamela-Cuixmala, Jalisco, Mexico. In El Jaguar en el Nuevo Milenio (eds R. Medellin, C. Equihua, C.L.B. Chetkiewicz, P.G. Crawshaw Jr, A. Rabinowitz, K.H. Redford, et al.), pp. 107-126. Fondo de Cultura Economica, Universidad Nacional Autonoma de Mexico, and Wildlife Conservation Society, Mexico.

Rabinowitz, A. \& Zeller, K.A. (2010) A range-wide model of landscape connectivity and conservation for the jaguar, Panthera onca. Biological Conservation, 143, 939-945.

Sanderson, E.W., Redford, K.H., Chetkiewicz, C.B., Medellin, R.A., Rabinowitz, A.R., Robinson, J.G. \& Taber, A.B. (2002) Planning to save a species: the jaguar as a model. Conservation Biology, 16, 58-72.

Soule, M.E. \& Mills, L.S. (1998) No need to isolate genetics. Science, $282,1658-1659$

Sunquist, M. \& Sunquist, F. (2002) Wild Cats of the World. University of Chicago Press, Chicago, USA.

Swank, W.G. \& Teer, J.G. (1989) Status of the jaguar - 1987. Oryx, 23, $14-21$.

Tejeda-Cruz, C., Naranjo, E.J., Cuaron, A.D., Perales, H. \& Cruz-Burguete, J.L. (2009) Habitat use of wild ungulates in fragmented landscapes of the Lacandon Forest, Southern Mexico. Mammalia, 73, 211-219.

Weckel, M., Giuliano, W. \& Silver, S. (2006) Cockscomb revisited: Jaguar diet in the Cockscomb Basin Wildlife Sanctuary, Belize. Biotropica, 38, 687-690.

Zeller, K.A., Nijhawan, S., Salom-Pérez, R., Potosme, S.H. \& Hines, J.E. (2011) Integrating occupancy modeling and interview data for corridor identification: a case study for jaguars in Nicaragua. Biological Conservation, 144, 892-901. 


\section{Biographical sketches}

Lisanne Petracca is a geospatial analyst who specializes in geographical information systems, remote sensing and site occupancybased analyses of habitat use by the jaguar and its prey. O. ERIC RAMIREZ-BRAVO works on various carnivore conservation projects in central Mexico and is director of fauna-related projects for the NGO CREANATURA. LORNA HERNÁNDEZ-SANTÍn is a wildlife biologist specializing in carnivore research and geographical information systems analysis. She also studies biodiversity within humandominated landscapes, with a goal of reducing human influence on wildlife. 